\title{
A Review of ARM Processor Architecture History, Progress and Applications ${ }^{a}$ Muhammad Nabeel Asghar, ${ }^{\mathrm{b}}$ Muhammad Umar Chaudhry, ${ }^{\mathrm{c}}$ Najeeb UI Hussan, ${ }^{\mathrm{d}}$ Muhammad Yasir, "Sumayya Bibi
}

\author{
a: Department of Computer Science, Bahauddin Zakariya University Multan; \\ nabeel.asghar@bzu.edu.pk \\ b: AiHawks, Multan 60000, umarch@skku.edu, Pakistan \\ c: Cyber Crime Analyst at Cyber Crime Wing FIA najeebulhussan@ gmail.com \\ d: Department of Computer Science, University of Engineering and Technology Lahore, Faisalabad \\ Campus; muhammadyasir@uet.edu.pk \\ e: Department of Electrical Engineering, B.Z University Multan; sumayyabibi@bzu.edu.pk
}

Abstract: Globally, over 50 billion ARM architecture based embedded chips of 32-bit and 64-bit instruction set architecture are commonly used and produced in quantity perspective since 2014. In our daily life most of the people uses and depends upon a penalty of electrical and automotive devices which have now become an essential part of their daily life. Due to that reason embedded processors are used to build such devices which takes less silicone-space, provides efficient processing and less power.

Keywords - ARM history, RISC processor, modes of operation, ARM versions, CISC architecture, CPSR register, ARM Applications, $A R M$ profile ARM architecture,, Cortex-R, Cortex $M$, Cortex-A, etc.

\section{i. INTRODUCTION}

Acorn RISC Machine, later Advanced RISC Machine is widely used reduced instruction set computer (RISC) family of computer processors, system on chip, system on module, smart phones, configured for various environment[1]. Acorn Computers firstly used the acronym ARM Acorn RISC Machine in 1983. In 1990 it was changed to "Advanced RISC Machines" due to incorporated of the company "Advanced RISC Machines Ltd." by the time of Initial Public Offering, Company name was modified to "ARM Holdings" surprisingly Apple was the joint venture partner at that time and has a long history with ARM[2].Which is now owned by Japanese tele communions company "Softbank Group"[1]. Currently, ARM is world's top

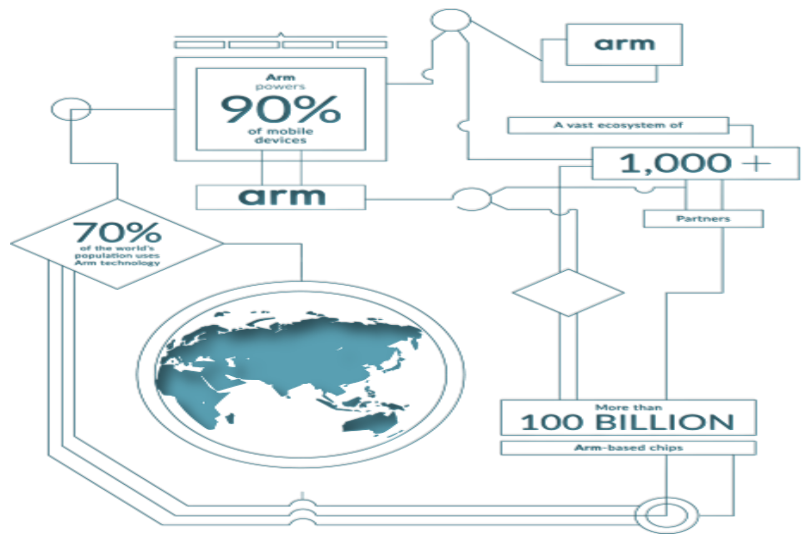

Figure 1 ARM ECO SYSTEM

semiconductor IP Company who has shipped about 100 billion ARM based processors to date and has more than 1,100 partners. More than $95 \%$ mobile devices are using the ARM powered processor[3]. 
As compared to CISC architecture which is more emphasis on hardware RISC architecture based processor has required fewer transistors and less silicon area. [12] In order to enhance the performance functions (floating point hardware, memory management functions, cache memory) of system a huge area of board is left free in RISC CPU Which brings improvement in cost, power consumption, and heat dissipation[4].

\section{ii. FEATURES OF ARM ARCHITECTURE}

When the primary ARM processor was introduced, only instances of reduced instruction set computing processor (RISC) were the Stanford MIPS and Berkeley reduced instruction set computing Processor. The ARM design has taken some of the features from Berkeley RISC design like a uniform register file load store architecture, 32-bit fixedlength instruction, and 3-address instruction formats[5].ARM architectural licensing provides the facility of designing their own processor cores with the help of instruction set of ARM. Such as Al-catel, Apple, Applied Micro, Atmel, Broadcom, Ca- vium, Nvidia, Nxp, Qualcomm Kyro, Raspberry Pi and Samsung electronics, X-Gene [6][7]

ARM architecture, blending of the simple hard- ware instruction sets that's stranded in RISC ideas but recalls some of key CISC features, such as improved code density, has made the ARM more power efficient and result in small silicone size (Furber) (Yokoyama, Schulze, Borges, \& Mc Evoy, 2019). Embedded application gets the advantage of low cost and construction of simple pipeline.

\section{iii. ARM ARCHITECTURE}

Improvements in architecture of RISC allows Arm processors to achieve balance in less size of code, high performance, lowering the power consumption, and less region of silicon. Arm architecture has progressed with passing time, incorporating many levels of architecture in its history which are as follows [8].

- Security Extensions (Trust -Zone technology)

- Advanced-SIMD (NEON technology)[9]
- Virtualization-Extensions, introduced in Armv7A.[10]

- Crypto-Extensions, part of Armv8-A (ARM, developer.arm.com, n.d.).

ARM produces an entire family of CPUs that share shared (ISA) instruction sets architecture and programmer's models which have backward compatibility. CPUs applying the Arm Architecture follow to a particular series of the architecture[11]. Which are:

- ('A') profile or Architectural profile, is used for high performance industries such as mobile and enterprise.

- ('R') profile or Real-Time profile, used for embedded applications, healthcare, automotive and industrial control.

- ('M') Microcontroller profile or profile, used in the microcontroller, wearable, Internet of Things, single processing like controlling motor and power, sensor fusion [12].

The latest architecture Armv8 series architecture has three variations of the architecture relating processors aiming different markets:

- Latest generation of Arm architecture in Aprofile is Armv8-A It indicate the overview of a 64-bit architecture beside the firm 32bit architecture, and allows multiple stages of AArch32 and AArch64 support.

- Latest generation of Arm architecture in Rprofile is Armv8- $\mathrm{R}$. This architecture involved a Memory Protection Unit (MPU) and deterministic memory structure and supports the A32 and T32 instruction-sets architecture[13].

- Latest generation of Arm architecture in M-profile is Armv8-M.its mostly used in low cost embedded systems.it also sup- port to other profiles by different exception handling technique and bring sup- ports to T32 instruction sets architecture[14]. 


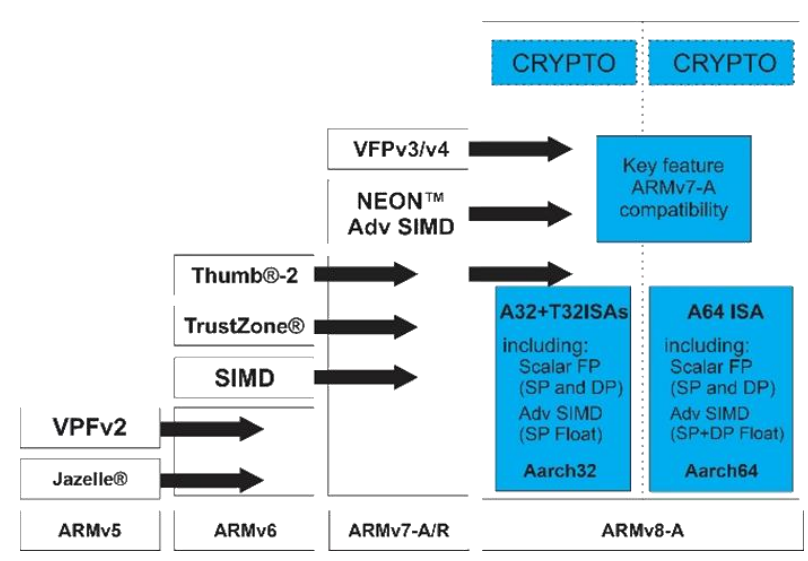

Figure 2 ARM architecture evolution [3]

\section{iv. ARM INSTRUCTION SET}

ARM processors supports following 3 type of architecture instruction sets.

- A32 Instruction Set (A32-IS)

- T32 Instruction-Set (T32-IS)

- A64 Instruction-Set (A64-IS)

\section{A32 Instruction-Set}

A32 instructions or ARM instructions in preARMv8 architectures, are 32 bits wide, and are line up on

4-byte boundaries. A32 instructions only runs when previous instruction have set to special con- dition code such as N, Z, C and V flags[6]
The main support of A64-IS is the architecture of ARMv8-A and it Important feature are following:

- 5-bit clean decoder table based register specifiers.

- A32 and T32 Instruction

- 64-bit general purpose registers accessible at any time (total $=31$ ).

- For improvement in performance and energy of general purpose registers modal banking is not implemented.

- Dedicated, zero-register available for ut-

- most instructions [6]

\section{v. ARM PROCESSOR MODES OF OPERATION}

ARM used seven operating modes .Respectively has access to its individual stack space and a different subset of registers.

\begin{tabular}{|c|c|c|}
\hline Mode & Description & \\
\hline $\begin{array}{l}\text { Supervisor } \\
\text { (SVC) }\end{array}$ & $\begin{array}{l}\text { Entered on reset and when a Supervisor call } \\
\text { instruction (SVC) is executed }\end{array}$ & \multirow{3}{*}{$\begin{array}{l}\text { Privileged } \\
\text { modes }\end{array}$} \\
\hline $\begin{array}{l}\text { FIQ } \\
\text { IRQ } \\
\text { Abort } \\
\text { Undef }\end{array}$ & $\begin{array}{l}\text { Entered when a high priority (fast) interrupt is } \\
\text { raised } \\
\text { Entered when a normal priority interrupt raised } \\
\text { Used to handle memory access violations } \\
\text { Used to handle undefined instructions }\end{array}$ & \\
\hline System & $\begin{array}{l}\text { Privileged mode using the same registers as User } \\
\text { mode }\end{array}$ & \\
\hline User & $\begin{array}{l}\text { Mode under which most Applications/OS tasks } \\
\text { run }\end{array}$ & $\begin{array}{l}\text { Privileged } \\
\text { mode }\end{array}$ \\
\hline
\end{tabular}

Figure 4 ARM processor modes of operations [15]

\section{vi. IMPORTANT REGISTERS}

The internal hardware device of CPU is Register which not only stores binary data but also can be accessible rapidly than other locations in RAM. 13 general purpose registers are used in ARM like: One Stack Pointer (SP) and R0 to R12 registers. 1 Link Register (LR) R13. One Program Counter (PC), Return address of caller is hold by R14. One Current Program Status Register (CPSR) by register R15 [16], the ARMv6-M and ARMv7-M exception are, Banked SP and LR for two modes of supervisor registers. Two Banked SP and LR Abort Mode Registers. Two modes of undefined registers for the SP and LR banked. Two modes of interrupt 
register for SP and LR banked. Seven register of FIQ mode for R8-R12 banked, LR and SP. Two registers of monitor mode for SP and LR banked. Six Saved Program Status Registers (SPSRs), 1 exception mode [16].

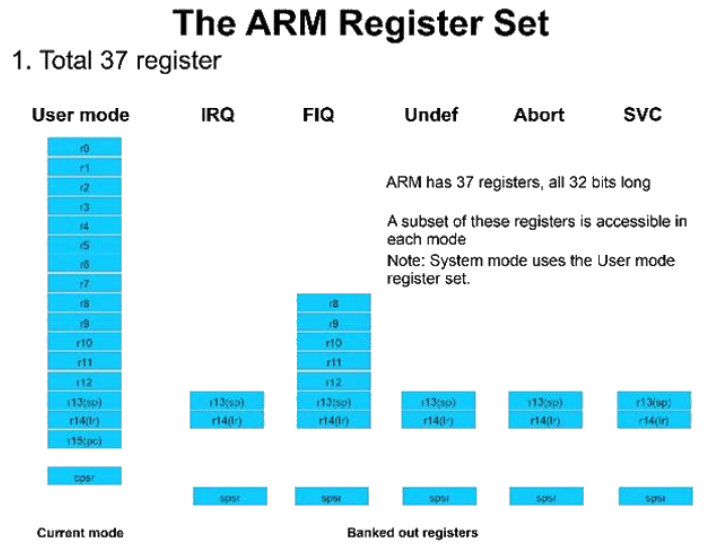

Figure 5 ARM processor important registers [19]

The 32-bit and 64-bit series of RISC ARM Processor cores is of ARM Cortex-A which are used for applications consisting of 32-bit ARM Cortex (A5, A7-A9, A12, A15, A17) and 64-bit ARM Cortex (A53, A57,A72)[10] [18].

Application includes

- Server

- Automotive

- Embedded

- Smartphones

- Intelligent devices in your home

- Large-screen compute

\section{vii. APPLICATION DOMAINS OF ARM PROCESSOR}

Following are the application series of Cortex processor.

\section{- Arm Cortex-A Series Processors}

Cortex-A series, deliver a range of solutions for devices responsible for the tasks of complex computing, like: rich Operating System (OS) hosting platform, and support of different software applications[17]

\section{ARM Cortex-A75}

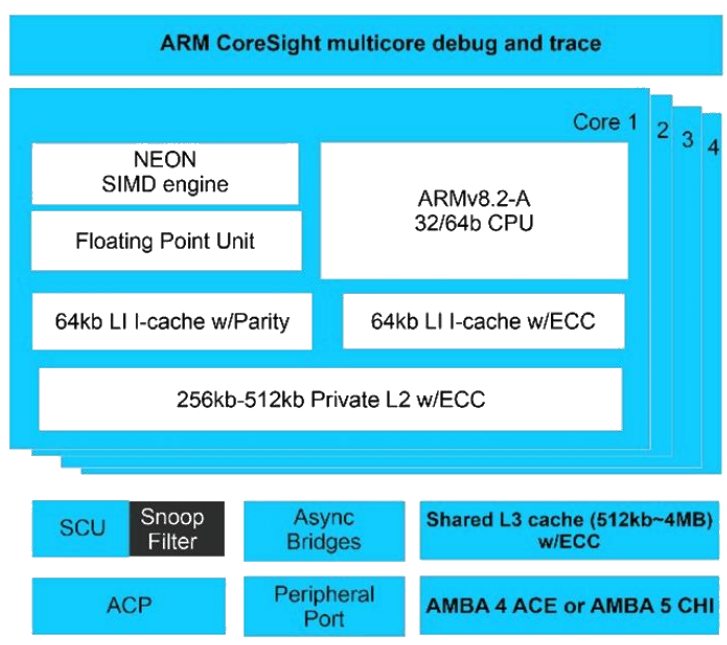

Figure 66 ARM Cortex-A75 CoreSight p[5] 
Table 1 ARMv8-A Architecture featues comaparison [1]

\begin{tabular}{|c|c|c|c|c|c|c|c|c|c|c|c|}
\hline Core & $\begin{array}{l}\text { Relea } \\
\text { se }\end{array}$ & $\begin{array}{l}\text { Revisi } \\
\text { on }\end{array}$ & $\begin{array}{l}\text { Deco } \\
\text { de }\end{array}$ & $\begin{array}{l}\text { Pipel } \\
\text { ine } \\
\text { dept } \\
\text { h }\end{array}$ & $\begin{array}{l}\text { Out } \\
\text { of } \\
\text { order } \\
\text { Exec } \\
\text { ution } \\
\end{array}$ & $\begin{array}{l}\text { Branc } \\
\text { h } \\
\text { Predic } \\
\text { tion }\end{array}$ & $\begin{array}{l}\text { Execut } \\
\text { ion } \\
\text { port }\end{array}$ & $\begin{array}{l}\text { L0 } \\
\text { Cac } \\
\text { he }\end{array}$ & $\begin{array}{l}\text { L1 } \\
\text { Cache } \\
\text { Inst + } \\
\text { data } \\
\text { (in KiB) }\end{array}$ & L2 Cache & $\begin{array}{l}\text { L3 } \\
\text { Cache }\end{array}$ \\
\hline $\begin{array}{l}\text { Corte } \\
x- \\
\text { A75 }\end{array}$ & 2017 & $\begin{array}{l}\text { ARMv8 } \\
.2-\mathrm{A}\end{array}$ & $\begin{array}{l}\text { 3- } \\
\text { wide }\end{array}$ & $11-13$ & $\begin{array}{l}\text { Yes } \\
\text { 6-wide } \\
\text { dispat } \\
\text { ch }\end{array}$ & $\begin{array}{l}\text { Two- } \\
\text { level }\end{array}$ & $8 ?$ & No & $64+64$ & $\begin{array}{l}256- \\
512 \mathrm{KiB} / \mathrm{co} \\
\text { re }\end{array}$ & $\begin{array}{l}0-4 \\
\mathrm{MiB}\end{array}$ \\
\hline $\begin{array}{l}\text { Corte } \\
x- \\
\text { A76 }\end{array}$ & 2018 & $\begin{array}{l}\text { ARMv8 } \\
.2-\mathrm{A}\end{array}$ & $\begin{array}{l}4- \\
\text { wide }\end{array}$ & $11-13$ & $\begin{array}{l}\text { Yes } \\
\text { 8-wide } \\
\text { dispat } \\
\text { ch }\end{array}$ & $\begin{array}{l}\text { Two- } \\
\text { level }\end{array}$ & 8 & No & $64+64$ & $\begin{array}{l}256+512 \mathrm{Ki} \\
\mathrm{B} / \text { core }\end{array}$ & $\begin{array}{l}1-4 \\
\mathrm{MiB}\end{array}$ \\
\hline $\begin{array}{l}\text { Corte } \\
x- \\
\text { A77 }\end{array}$ & 2019 & $\begin{array}{l}\text { ARMv8 } \\
.2-\mathrm{A}\end{array}$ & $\begin{array}{l}4- \\
\text { wide }\end{array}$ & $11-13$ & $\begin{array}{l}\text { Yes } \\
10- \\
\text { wide } \\
\text { dispat } \\
\text { ch }\end{array}$ & $\begin{array}{l}\text { Two- } \\
\text { level }\end{array}$ & 12 & $\begin{array}{l}1.5 \mathrm{~K} \\
\text { entri } \\
\text { es }\end{array}$ & $64+64$ & $\begin{array}{l}256+512 \\
\mathrm{KiB} / \text { core }\end{array}$ & $\begin{array}{l}1-4 \\
\mathrm{MiB}\end{array}$ \\
\hline
\end{tabular}

\section{- ARM CORTEX-R SERIES PROCESSORS}

Cortex-R series, deliver fast and deterministic pro- cessing and high performance, while meeting chal- lenging real-time constraints in a range of situa- tions. They combine those features in a perfor- mance, power and area optimization, making them the trusted choice in consistent systems demanding high error resistance[13]. Important series of cortex-R processors are Cortex-(R4,R5,R7,R8) and most advanced processor of this series is Cortex-R52 [7]Application includes:

- Automotive

- Robotics

- Industrial

- Transportation

- Healthcare 
- Building automation

\section{ARM}

Cortex-R52

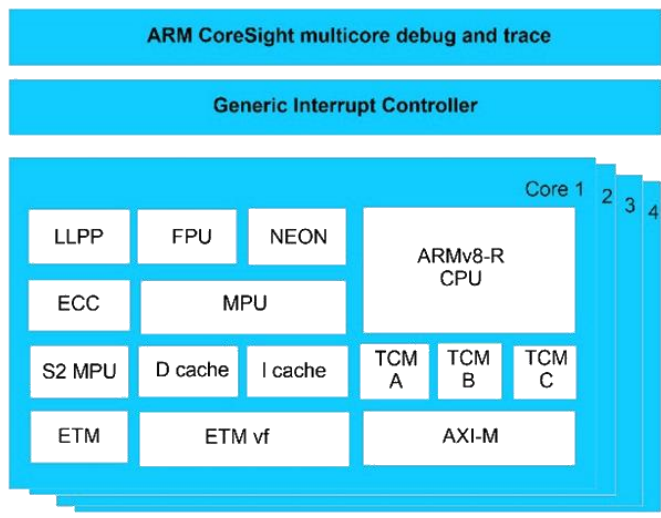

AXI-S

Figure 7 ARM Cortex-R52 CoreSight [3]

\section{ARM}

Cortex®-M33

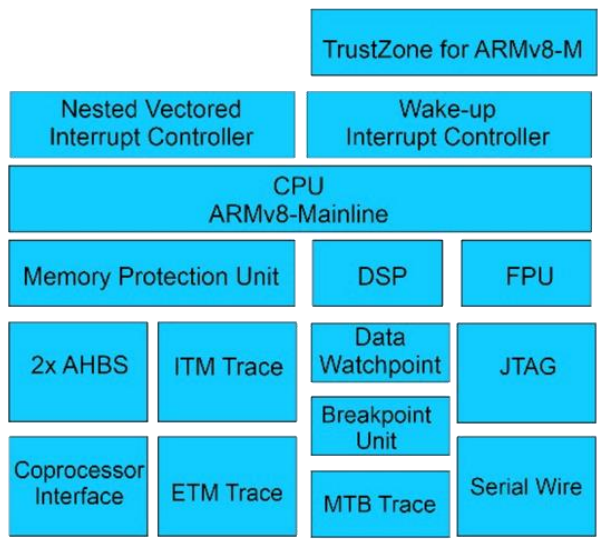

Figure 8 CHIP BLOCK DIAGRAM of Cortex-M33[3] 
Table 2 Cortex ARMv8-R Architecture features comaparison [1]

\begin{tabular}{|c|c|c|c|c|c|c|c|}
\hline \multirow{2}{*}{$\begin{array}{c}\text { ARM } \\
\text { Family } \\
\text { Cortex-R }\end{array}$} & \multicolumn{2}{|c|}{ ARM Architecture } & \multirow{2}{*}{$\begin{array}{c}\text { ARM } \\
\text { core }\end{array}$} & \multirow[b]{2}{*}{$\begin{array}{l}\quad \text { Release } \\
\text { Thumb/Thumb- } \\
\text { 2/DSP/optional VFPv3 } \\
\text { FPU \& Precision, 11- } \\
\text { stage pipeline dual } \\
\text { core running lockstep } \\
\text { with fault logic/out of } \\
\text { order } \\
\text { execution/dynamic } \\
\text { registered } \\
\text { renaming/optional as } 2 \\
\text { independent core, } \\
\text { Real-time profile, }\end{array}$} & \multirow{2}{*}{\multicolumn{2}{|c|}{\begin{tabular}{c|c} 
Features & $\begin{array}{c}\text { Cache } \\
\text { (I/D), } \\
\text { MMU }\end{array}$ \\
0-64KB/0-64KB.? of 0- \\
128KB TCM, opt. MPU \\
with 16 regions.
\end{tabular}}} & \multirow{2}{*}{ 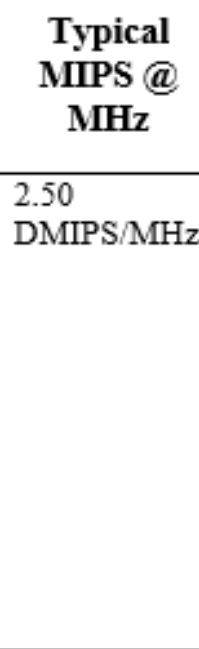 } \\
\hline & $\begin{array}{l}\text { ARMv7- } \\
\text { R }\end{array}$ & $\begin{array}{l}\text { Cortex- } \\
\text { R7 }\end{array}$ & & & & & \\
\hline Cortex-R & $\begin{array}{l}\mathrm{ARMv} 7- \\
\mathrm{R}\end{array}$ & $\begin{array}{l}\text { Cortex- } \\
\text { RS }\end{array}$ & 2016 & $\begin{array}{l}\text { Thumb-2, DSP, opt. } \\
\text { floating-point with } \\
\text { single \& double } \\
\text { precision, 11-stages } \\
\text { pipeline with } \\
\text { instruction per-fetch, } \\
\text { MPU. }\end{array}$ & $\begin{array}{l}4-64 \mathrm{~KB}, \mathrm{TCM} \\
\text { with } 24 \text { region }\end{array}$ & B), MPU & $\begin{array}{l}2.50 \\
\mathrm{DMIS} / \mathrm{MHz}\end{array}$ \\
\hline Cortex-R & $\begin{array}{l}\text { ARMv8- } \\
\text { R }\end{array}$ & $\begin{array}{l}\text { Cortex- } \\
\text { R52 }\end{array}$ & 2018 & $\begin{array}{l}\text { Thumb-2, DSP, } \\
\text { Floating-point with } \\
\text { single \& double } \\
\text { precision and Neon, 8- } \\
\text { stages pipeline with } \\
\text { instruction per-fetch, } \\
\text { Dual core lockstep, } \\
\text { MPU. }\end{array}$ & $\begin{array}{l}\mathrm{K}-32 \mathrm{~K}, 3 \mathrm{TC} \\
\text { Level } 1 \mathrm{MPU} \\
\text { \& down } 64 \text {-by } \\
\text { MPU ( } 24 \text { regi } \\
\text { little as 64-byt }\end{array}$ & $\begin{array}{l}\text { MB), } \\
\text { gions up } \\
\text { Level } 2 \\
\text { ith a }\end{array}$ & $\begin{array}{l}2.16 \\
\mathrm{DMIPS} / \mathrm{MHz}\end{array}$ \\
\hline
\end{tabular}

\section{Arm Cortex-M Series Processors}

Improved for cost and power-sensitive microchip control unit (MCU) devices for applications of IoT, motor control, connectivity, smart metering, human interface devices, automotive and industrial control systems and medical instrumentation[19].

Important cortex-M series processor are:

SC300 Processor, SC000 Processor, Arm Design Start, Cortex-(M0,M3,M0+,M4,M7, and M23) and the most latest and advanced processor of this series is Cortex-M33[12]. Application includes

- Processing of Audio

- Smart home/building/planet/enterprise

- Wearables and Sensor fusion

- control

- Internet of Things

- Single processing such as power and motor

- Connectivity 
Table 3 Cortex ARMv8-M Architecture features comparison[3]

\begin{tabular}{|c|c|c|c|c|c|c|}
\hline $\begin{array}{c}\text { ARM } \\
\text { Family }\end{array}$ & $\begin{array}{c}\text { ARM } \\
\text { Architecture }\end{array}$ & $\begin{array}{c}\text { ARM } \\
\text { core }\end{array}$ & Release & Feature & Cache(I/D),MMU & $\begin{array}{c}\text { Typical } \\
\text { MIPS @ } \\
\text { MHz }\end{array}$ \\
\hline Cortex-M & ARMv8-M & $\begin{array}{l}\text { Cortex- } \\
\text { M23 }\end{array}$ & 2016 & $\begin{array}{l}\text { Thumb-1 (most), } \\
\text { Thumb-2 (sum), } \\
\text { Trust zone, divide, } \\
\text { Microcontroller } \\
\text { profile }\end{array}$ & $\begin{array}{l}\text { No TCM, } 16 \text { regions } \\
\text { MPU (optional), } \\
\text { Cache (Optional) }\end{array}$ & $\begin{array}{l}0.99 \\
\text { DMIPS/MHz }\end{array}$ \\
\hline Cortex-M & ARMv8-M & $\begin{array}{l}\text { Cortex- } \\
\text { M33 }\end{array}$ & 2016 & $\begin{array}{l}\text { Thumb-1, Thumb-2, } \\
\text { Saturated, Divide, } \\
\text { FPU(SP), Co- } \\
\text { processor, } \\
\text { Microcontroller } \\
\text { profile, DSP, } \\
\text { TrustZone }\end{array}$ & $\begin{array}{l}\text { No TCM, } 16 \text { regions } \\
\text { MPU (optional), } \\
\text { Cache (Optional) }\end{array}$ & $\begin{array}{l}1.50 \\
\mathrm{DMIPS} / \mathrm{MHz}\end{array}$ \\
\hline Cortex-M & ARMv8-M & $\begin{array}{l}\text { Cortex- } \\
\text { M35P }\end{array}$ & 2019 & $\begin{array}{l}\text { Thumb-1, Thumb-2, } \\
\text { Saturated, DSP, } \\
\text { FPU(SP), TrustZone, } \\
\text { Microcontroller } \\
\text { profile, Co-processor, } \\
\text { Divide }\end{array}$ & $\begin{array}{l}\text { Cache built in } \\
\text { (optional 2-16KB),I- } \\
\text { cache, no TCM, } 16 \\
\text { regions MPU } \\
\text { (optional) }\end{array}$ & $\begin{array}{l}1.50 \\
\mathrm{DMIPS} / \mathrm{MHz}\end{array}$ \\
\hline
\end{tabular}

\section{viii. CONCLUSION}

ARM architecture, blending of the simple hardware instruction sets that's stranded in RISC ideas but recalls some of key CISC features, such as improved code density, has made the ARM more power efficient and result in small silicone size. It is simple pipeline construction which is low cost and adds efficiency to modern VLSI technology and embedded applications and these technologies permits huge number of further components of system which can be incorporated on the same chip. The current low end ARM core is ARM9TDMI which is used excessively by a range of applications and also supports ARM 32-bit and Thumb instruction set of 16 bits which allows the user to tradeoff between density of high code and high performance. Most of the smartphones and electronics gadget which is the part of our daily life are now using this power. ARM processors towards ARM9 uses pipeline of 5 stages like: fetching, decoding, execution, data memory access and register write. 


\section{ix. REFERENCES}

[1] X. Gong, Z. Shao, Q. Du, A. Yu, and J. Zhang, "Performance overhead analysis of virtualisation on ARM," Int. J. Inf. Commun. Technol., vol. 12, no. 1-2, pp. 143-161, 2018.

[2] S. Harris and D. Harris, Digital design and computer architecture: arm edition. Morgan Kaufmann, 2015.

[3] B. Saeedi, "Comparison between Intel®Atom ${ }^{\mathrm{TM}}$ and ARM Cortex-A53."

[4] H. Seo, "Memory efficient implementation of modular multiplication for 32-bit ARM Cortex-M4," Appl. Sci., vol. 10, no. 4, 2020, doi: 10.3390/app10041539.

[5] M. Crinson, Modern architecture and the end of empire. Routledge, 2017.

[6] N. Zlatanov, "ARM Architecture and RISC Applications." 2016.

[7] J. Grant, "Parallel Performance of ARM ThunderX2 for Atomistic Simulation Algorithms," no. 1.

[8] D. Yokoyama, B. Schulze, F. Borges, and G. Mc Evoy, The survey on ARM processors for $H P C$, vol. 75, no. 10. Springer US, 2019.

[9] E. Limonova, A. Terekhin, D. Nikolaev, and V. Arlazarov, "Fast implementation of morphological filtering using arm neon extension," Int. J. Appl. Eng. Res., vol. 11, no. 24, pp. 11675-11680, 2016.

[10] C. Lin, H. Qian, and Z. Wang, "A HighThroughout Real-Time Prewitt Operator on Embedded NEON+ ARM System," in 2018 IEEE Asia Pacific Conference on Circuits and Systems (APCCAS), 2018, pp. 270-273.

[11] N. Liu, M. Yu, W. Zang, and R. Sandhu, "On the Cost-Effectiveness of TrustZone Defense on ARM Platform," pp. 1-12.

[12] A. Reid, "Who guards the guards? Formal validation of the Arm v8-M architecture specification," Proc. ACM Program. Lang., vol. 1, no. OOPSLA, p. 88, 2017.

[13] S. Lee and H. Yoo, "ARM Cortex-M0 DesignStart를 활용한 커스텀 시스템 설계 및 검증 Custom system design and verification using ARM Cortex-M0 DesignStart," vol. 24, no. 2, 2020.

[14] S. McIntosh-Smith, J. Price, T. Deakin, and
A. Poenaru, "A performance analysis of the first generation of HPC-optimized Arm processors," Concurr. Comput., vol. 31, no. 16, pp. 1-13, 2019, doi: 10.1002/cpe.5110.

[15] S. Aslan and S. C. \.Ileri, "Performance Analysis of ARM big. LITTLE Architecture Based Mobile Processor with Multi-thread Face Detection," in 2019 4th International Conference on Computer Science and Engineering (UBMK), 2019, pp. 336-339.

[16] S. Pinto and N. Santos, "Demystifying Arm TrustZone: A Comprehensive Survey," ACM Comput. Surv., vol. 51, no. 6, p. 130, 2019.

[17] Y. M. P. Pa, S. Suzuki, K. Yoshioka, T. Matsumoto, T. Kasama, and C. Rossow, "IoTPOT: A novel honeypot for revealing current IoT threats," J. Inf. Process., 2016, doi: 10.2197/ipsjjip.24.522.

[18] A. Lessoff, "Art and Architecture," A Companion to Gilded Age Progress. Era, pp. 149-164, 2017, doi: 10.1002/9781118913994.ch12.

[19] “Audience The ARM," vol. 1, no. April, pp. 123-141, 1985.

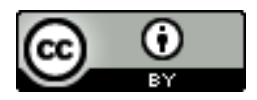

$\begin{array}{llr}\text { Journal of Applied } & \text { and } & \text { Emerging } \\ \text { Sciences by BUITEMS is } & \text { licensed } & \text { under } \\ \text { a Creative } \quad \text { Commons } & \text { Attribution } & 4.0 \\ \text { International License. } & & \end{array}$

